\title{
ORBITAL MYOSITIS ASSOCIATED WITH ACUTE SCLEROTENONITIS*
}

\author{
BY \\ SÜREYYA GÖRDÜREN \\ Department of Ophthalmology, University of Ankara, Turkey
}

Myositis has an important place among the orbital pseudo-tumours. According to François, Rabaey, and Evans (1956), it occurs in three forms: degenerative (congenital and acquired), acute, and chronic.

Although both the degenerative and acute forms of myositis may show evident causes, the aetiology of the rare chronic orbital myositis of the primary type is unknown, and the condition has been reported under many different names: orbital myositis (Offret, 1939), waxy degeneration (Zenker), pseudo-tumour (Benedict and Knight, 1923), idiopathic myositis (Gleason, 1903), and exophthalmic ophthalmoplegia (Brain and Turnbull, 1938). These names are listed by Dunnington and Berke (1943).

The first case report of this disease was made by Busse and Hocheim (1903). Offret (1939) collected 32 cases from the literature and added two of his own. Two further cases were reported by Michaïl and Rusu (1940), four by Dunnington and Berke (1943), one each by Valière-Vialeix (1948), Raverdino (1949), Guillot, Duplay, and Vigouroux (1949), and Kornblueth (1953), and four by Contino (1949). Besides these Artemev (1939) reported one, Babel (1946) one, Lisch (1952) two, and Voisin and Landrieu (1953) one, according to François and others (1956), who also reported three of their own. Vancea and Vaighel (1957) reported a case of orbital myositis with cellulitis, Mertens, Esslen, and Papst (1958) reported four cases, Papst, Mertens, and Esslen (1958) added three more, and Bertelsen (1960) reported six cases of acute sclerotenonitis with ocular myositis. Altogether about seventy cases are to be found in the literature.

Orbital myositis may show entirely different clinical forms and therefore some cases may be misdiagnosed even after careful investigation and operation (Valière-Vialeix, 1948; François and others, 1956; Vancea and Vaighel, 1957).

Pure orbital myositis is extremely rare. Bertelsen (1960) claimed that many cases reported in the literature were mostly complicated by associated sclerotenonitis or cellulitis.

A white and painless oedema of the lids, chemosis, ptosis, and an axial and direct exophthalmos are the common signs of ocular myositis. Sometimes a hard mass may be discovered by palpation which may lead to a 
diagnosis of malignancy but at the operation no mass is found except a fibrous thickening of the muscles. The condition is usually bilateral, but the second eye may be attacked only after a long interval. A biopsy may sometimes aggravate the signs.

The aetiology is still obscure. It is now clear that tuberculosis, syphilis, and focal infections play no important part in the disease. Poisoning, avitaminosis, heredity, allergy, glandular dysfunctions, infectious diseases, and trauma have also been suggested as aetiological factors. Offret's inflammation, Wells's lactic acid, and Marin's endocrine theories are the main suggestions that need to be considered.

The condition occurs mostly in males. The average age at onset is 40 , but Colley (1935) has seen it in a child aged 12 years.

Only one case (Gözcü, 1941) has so far been reported in Turkey, and the following case is the second.

\section{Case Report}

A 13-year-old boy was seen at the Eye Clinic, University of Ankara, on December 10, 1960, with exophthalmos of the left eye which had been noticed 20 days before, and a slight pain of 3 months' duration on the same side. He had been operated on at the clinic of oto-rhino-laryngology 6 days previously on the supposition that he had a tumour from the frontal or ethmoidal sinuses. No such mass was found to account for the condition, however, and he had therefore been transferred to the Eye Clinic. There was nothing important in his past medical history, and his general health was good.

Examination.-The right eye was normal with full vision. On the left side there was marked oedema of both lids and severe chemosis involving the inferior parts of the conjunctiva. The cornea could be seen only by lifting the upper lid. Movements of the globe were restricted and painful. A forward and slightly reducible exophthalmos was observed. Readings on the exophthalmometer (Hertel) were $16 \mathrm{~mm}$. for the right and $32 \mathrm{~mm}$. for the left (Fig. 1).

FIG. 1.- Left eye before operation, on December 10, 1960.

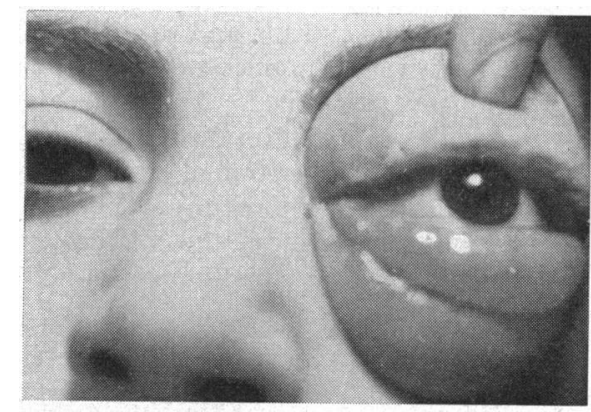

The anterior segment was normal, but fundus examination revealed blurring and oedema of the optic disc, tortuous veins, and retinal oedema. Vision was counting fingers from $5 \mathrm{~m}$. and 0.2 with $2.5 \mathrm{D}$ sph.

A hard mass was palpated along the inferior and temporal walls of the orbit.

Laboratory Investigations. - There was slight leucocytosis, an increased eosinopil count ( 5 per cent.), and an erythrocyte sedimentation rate of $110 \mathrm{~mm}$./hour. The other tests and investigations revealed nothing beyond normal limits. 
Treatment.-No improvement was obtained by the application of penicillin and terramycin, and on December 20, a subperiosteal inferior orbitotomy was performed and a biopsy taken. Microscopy of the muscle tissue showed dense fibrosis, hyaline degeneration, and a lymphohistiocytic inflammatory infiltration, including frequent lymphocytic follicles, leading to a diagnosis of orbital myositis (Institute of Pathology, University of Ankara, Prof. Dr. M. Köksal).

On January 9, 1961, the condition became more severe, chemosis increased (Fig. 2), and pain was more marked. A tarsorrhaphy was performed, but chemosis soon ruptured it.

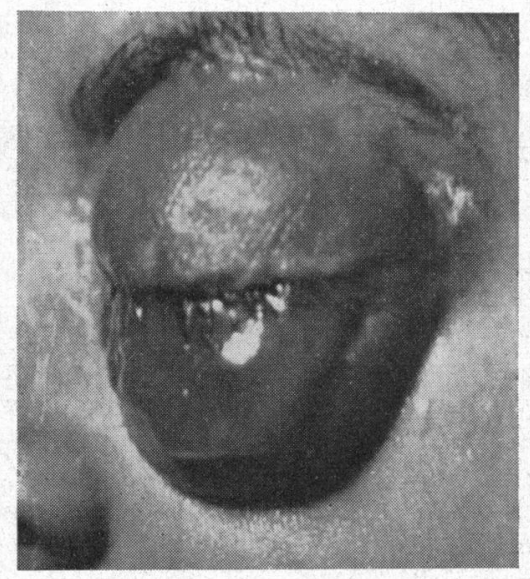
Fig. 2.-Left eye after biopsy, on January
9, 1961.

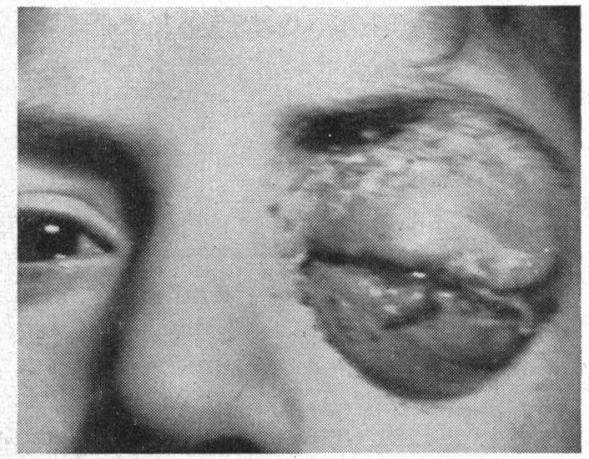

Fig. 3.-Left eye after orbitotomy and extirpation of muscles, on January 26, 1961.

On January 26, 1961, an inferior orbitotomy was performed with the object of extirpating the muscles involved. The internal, external, and superior recti had thickened into solid cartilagenous tissue and were scarcely recognizable. The inferior rectus was normal near its insertion, but a severe reaction had produced dense fibrosis towards the optic nerve. Tenon's capsule and the sclera were also implicated.

The four rectus muscles were dissected as far as possible and removed. A firm tarsorraphy was performed. The patient recovered from the operation and the palpebral and conjunctival reaction dwindled (Fig. 3).

Histopathological examination of the extirpated muscles showed wide destruction and fragmentation of the fibres, together with vacuolization, hyaline degeneration, and infiltration of round cells among the collagen tissue (Figs 4 and 5, opposite). Orbital myositis was again diagnosed (Institute of Pathology, University of Ankara, Prof. Dr. N. Eranil).

Progress.-On February 28, 1961, the patient was discharged, but on April 4, 1961, he returned with the report that 4 days before both eyes had become painful, and the vision was suddenly and severely diminished in the right eye.

Right Eye.-Oedematous lids, restricted painful ocular movements, and slight chemosis, with an exophthalmos of $22 \mathrm{~mm}$. (Hertel). A hard mass could be palpated around the rectus muscle insertions. The fundus was normal. Visual acuity was counting fingers at $2 \cdot 5 \mathrm{~m}$. (Fig. 6, opposite).

Left Eye.-Lids hypertrophic and immobile and eye movements absent, with an exophthalmos of $29 \mathrm{~mm}$. (Hertel). The anterior segment was normal, except for posterior synechiae and a few lens opacities. Fundus examination showed a pale disc and atrophic 
FIG. 4.-Histopathological appearance. $\times 100$.
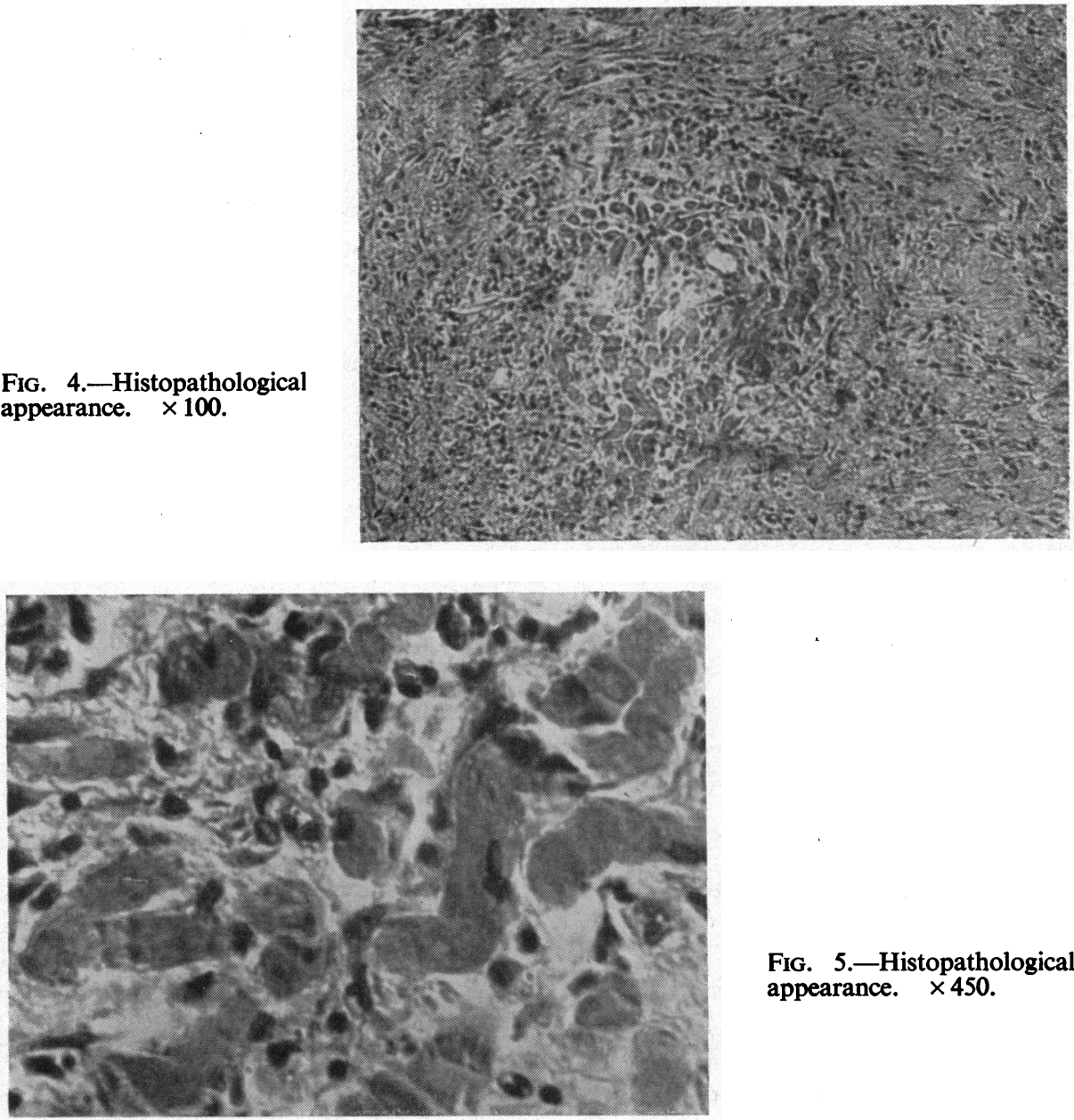

Fig. 5.-Histopathological appearance. $\times 450$.

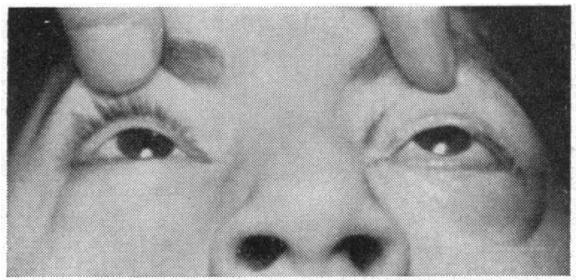

FIG. 6.-Involvement of the right eye, on April 17, 1961.

retina, with tortuosity of veins. The visual acuity was counting fingers at $1.5 \mathrm{~m}$. The general aspect of this eye, however, seemed very much improved.

Treatment.-He was immediately given oral Dexamethasone (Decadron) $4 \mathrm{mg}$. daily, $1 \mathrm{~g}$. Sigmamycin, $250 \mathrm{mg}$. vitamin $B_{1}$ and $1,000 \mu \mathrm{g}$. vitamin $B_{12}$. 
3 days later macular oedema and tortuosity of the veins were observed and vision had diminished to counting fingers at $50 \mathrm{~cm}$., but the general condition had improved, the oedema of the lids and exophthalmos had diminished, and the pain had ceased.

Result.-When the patient was last seen on April 17, the exophthalmos was $18 \mathrm{~mm}$. (Hertel) and the external parts of the right eye were normal. The fundus showed no pathological signs, but the vision did not improve to more than $0 \cdot 1$. No change could be detected in the left eye.

\section{Summary}

A case is presented of orbital myositis with acute sclerotenonitis shown by the very severe fibrous reactions which had spread to the sclera and to Tenon's capsule.

Corticosteroid therapy, applied when the second eye became involved, rapidly gave a favourable result; the patient soon recovered but his vision remained impaired.

\section{REFERENCES}

Artemev, N. I. (1939). Vestn. Oftal., 14, 31 (Abstracted in Zbl. Ophthal., 44, 22 (1940)).

Babel, J. (1946). Anm Oculist. (Paris), 179, 540.

Benedict, W. L., and KNIGHT, M. S. (1923), Arch. Ophthal. (N.Y.), 52, 582.

Bertelsen, T. I. (1960). Acta ophthal. (Kbh.), 38, 136.

Brain, W. R., and Turnbull, H. M., (1938). Quart. J. Med., n.s. 7, 293.

BusSe and Hochнеiм (1903). v. Graefes Arch. Ophthal., 55, pt. 2, p. 222.

Colley, T. (1935). Brit. J. Ophthal., 19, 93.

Contino, F. (1949). Ophthal. Lit. (Lond.), 3, No. 1916.

Dunnington, J. H., and Berke, R. N. (1943). Arch. Ophthal. (Chicago), 30, 446.

FrançoIs, J., RABAEY, M., and Evans, L. (1956). Ophthalmologica (Basel), 131, 105.

GleASON, J. E. (1903). Ophthal. Rec., 12, 471.

Gözcü, N. I. (1941). Türk. Oftal. Gaz., 3, 477.

Guillot, P. DuPlay, J., and Vigouroux, R. (1949). Rev. oto-neuro-ophthal., 21, 465. (Ophthal. Lit. (Lond.), 3, No. 4104).

Kornblueth, W. (1953). Acta med. orient., 12, 276. (Ophthal. Lit. (Lond.), 7, No. 2798).

LisCH, K. (1952). Ber. 57 Zusammenkunft dtsch. ophthal. Ges. 1951, p. 150.

Mertens, H. G., Esslen, E., and PAPST, W. (1958). Nervenarzt, 29, 120.

Michaïl, D., and Rusu, L. (1940). Ann. Oculist. (Paris), 177, 97.

OFFret, G. (1939). "Les myosites orbitaires". Doin, Paris.

Papst, W., Mertens, H. G., and Esslen, E. (1958). Klin. Mbl. Augenheilk., 133, 673.

Raverdino, E. (1949). "Atti 37 Cong. Soc. Oftal. Ital”., 10, 560. (Ophthal. Lit. (Lond.), 3, No. 4089).

Valière-Vialeix (1948). Ann. Oculist. (Paris), 181, 1.

VANCEA, M. P., and VAIGHel, V. (1957). Arch. Ophtal., 17, 791.

VoISIN, J., and LANDRIEU, P. (1953). Bull. Soc. ophtal. Fr., p. 700.

ZENKER, Cited by DUNNINGTON and BeRKe (1943), p. 459. 